\title{
Sintaxis oracional y construcción del texto en la prosa española del siglo de Oro
}

\author{
Rafael Cano Aguilar
}

0. De todos es bien sabida la dependencia que la Sintaxis histórica mantiene respecto de los textos literarios. Constituyen éstos su casi única fuente de datos; otros textos, como los de naturaleza jurídica o epistolar, a los que tan afecta es la Lingüística histórica, no son en el mejor de los casos sino apéndices de la lengua literaria, y por lo general su valor en este aspecto es mucho menor, ya que en ellos se reflejan de manera indirecta y mucho más pobre los procesos de innovación y evolución sintácticas. Ahora bien, no es sólo esta razón instrumental la que justifica dicha interrelación, lo cual suele traducirse en el hecho, ya señalado por Y. Malkiel ${ }^{1}$, de que las Historias de la lengua, iniciadas como "prehistorias de la lengua» (en donde se habla incluso de «otras» lenguas: p. ej., ibérico, vasco y celta como antesalas de la evolución del latín al romance castellano) acaban siendo «historias de la lengua literaria»: aparte de motivaciones más profundas, como las que tan acertadamente delimitó en su día R. Lapesa ${ }^{2}$, encontramos que en muchas ocasiones el historiador de la lengua y el de la literatura han de hablar de las mismas cosas, a propósito de las mismas realidades, si bien los objetivos de cada uno de ellos pueden diferir.

De acuerdo con la visión «sistemática» que ha dominado la Lingüística moderna, pero también la Gramática clásica, el historiador de la sintaxis de un idioma puede intentar establecer los procesos que han llevado a la configuración de los diversos paradigmas, estructuras y esquemas sintácticos que integran la estructura gramatical de esa lengua. El estudio de los cambios en los mecanismos de rección (preposicional o no,

\footnotetext{
1 "A Tentative Typology of Romance Historical Grammars", en Essays on Linguistic Themes, Oxford, 1968, págs. 71-164 (especialmente, págs. 136-138).

2 «Sobre problemas y métodos de una Sintaxis histórica», en Homenaje a Xavier Zubiri, Madrid, 1970, págs. 201-213.
} 
y con qué preposiciones) entre Verbos y sintagma Nominal, en las oposiciones de tiempos y modos verbales o en el sistema de nexos conjuntivos no parece presentar ninguno de los peligros de interferencia a que nos hemos referido al principio.

Ahora bien, el lingüista puede intentar esclarecer otras cuestiones, quizá de mayor importancia, y enfrentarse al proceso comunicativo, como interactuación de dos (o más) participantes, emisor(es), de papeles intercambiables, en situaciones de lo más variado, y con intenciones significativas que pueden, y suelen, ir mucho más allá de la simple comunicación, o información, de contenidos «referenciales». El lingüista se enfrenta así a la producción lingüística, por una parte, y a los actos en que esa actuación productiva se realiza, los textos, como segmentos temporales o espaciales en que dicha actividad toma forma concreta, por otra. De esta forma, diversas corrientes de la Lingüística de hoy, como la teoría de la enunciación o la Linguística del texto (aparte de otras direcciones como la Pragmática, etc. $)^{3}$ parecen volver a descender del universo abstracto (y reduccionista muchas veces) de los paradigmas, esquemas o moldes, de la langue, a la actuación del discurso «real», a la parole. Así, sólo en ese complejo entramado que acabamos de esbozar conciben muchos lingüistas actuales que puede entenderse cabalmente la función y el valor (en su sentido más amplio) de hechos lingüísticos como los mecanismos de actualización, los desplazamientos significativos en el verbo o las interferencias entre los distintos tipos de relación interoracional. En este sentido, pues, si el investigador en Sintaxis histórica adopta esta posición, no podrá estar sino muy próximo al estudioso de los textos literarios, pues tanto uno como otro han de intentar caracterizar los modos lingüísticos específicos con que se ha construido el texto al que se enfrentan, y en qué condiciones y situaciones se ha dado la producción de ese texto, con qué intención de sentido, etc. Sólo la preocupación estética, ausente en principio en el lingüista, puede diferenciar las perspectivas de análisis de uno y de otro. De hecho, algo así venía ya produciéndose en las tradicionales Historias de la lengua, pero con una oscilación de puntos de vista que no acababa de justificarse: así, la formación y desarrollo de una sintaxis cada vez más elaborada y compleja (desde el Poema del Cid a Alfonso X y después) se concebía más bien como objeto de análisis del lingüista, ya que tales procesos se referían a la lengua como tal; sin embargo, fenómenos semejantes en los hermanos Valdés, el Lazarillo o fray Luis de León se veían sólo en su dimensión literaria y estética, en la conformación de estilos individuales movidos por la preocupación de belleza (o semejantes).

Si nos volvemos hacia otra de las direcciones que la Lingüística, y en especial la Sintaxis, de hoy parecen estar recuperando cada vez con más interés: el análisis del coloquio ${ }^{4}$, nos encontramos con una situación muy semejante. Es cierto que el coloquio cae fuera de lo estrictamente «literario» (salvo coloquios ficticios o el «coloquialismo» en literatura), pero la posición del investigador apenas difiere de la señalada más arriba:

${ }^{3}$ T. Todorov (ed.) L'énonciation, en Langages, 17, 1970; T. A. Van Dijk, Texto y contexto (trad. de J. DomingoMoyano), Madrid: Cátedra, 1980; E. Bemárdez, Introducción a la lingüística del texo, Madrid: EspasaCalpe, 1982; E. Bustos, Pragmática del español, Madrid: UNED, 1986, etc.

${ }^{4}$ A. Narbona, «Sintaxis coloquial: Problemas y métodos», en Sintaxis española: nuevos y viejos enfoques, Barcelona: Ariel, 1989, págs. 149-169. 
ha de analizar también una compleja interacción entre los participantes en esta actuación comunicativa, y establecer los modos linguísticos que configuran dicha actuación; como ha sido señalado varias veces, el conocimiento de los esquemas linguísticos no suele servir de gran ayuda para comprender su puesta en funcionamiento en el coloquio, o para conocer las propias estructuras que éste genera: así, se ha dicho que la descripción habitual de la coordinación en las Gramáticas apenas nos aclara la función y sentido que las estructuras «coordinadas» presentan en el coloquio. Esta perspectiva de la Sintaxis de hoy no hace sino reforzar la actitud que señalamos para el estudioso de la Sintaxis histórica: es cierto que éste carece de coloquios «reales» que analizar (aparte de los creados en literatura: esto vuelve a acercar posturas), pero el punto de partida es nuevamente el de quien se enfrenta con un producto lingüístico que ha de estudiar, para poder comprenderlo, dentro de su proceso de producción. No otra es, como hemos dicho, la situación del estudioso de los textos literarios.

No por casualidad el único periodo de relativo auge de la Sintaxis histórica coincidió con los años en que dominó en buena parte de Europa (en especial, en Alemania, Italia y España) el llamado idealismo lingüístico. Para estos idealistas, el lenguaje se concebía fundamentalmente como actividad creativa del individuo, sobre todo de ciertos individuos, creación de contenidos y formas: los resultados de esta creación se transmitían, como productos ya hechos, como técnicas del hablar, a nuevos hablantes y situaciones, que podían reproducir o no las condiciones originarias. Por ello, desarrollaron sobre todo la Estilística, más atenta a la vertiente creadora del individuo, y la Sintaxis, preocupada de la fijación de esas creaciones en el acervo lingüístico de la comunidad, muchas veces como manifestación de la peculiaridad espiritual, la «genialidad», de ésta. Ciertamente, es ésta una ideología hoy eliminada; pero su atención al texto y alas condiciones en que éste surge hace que no debamos relegarla por enteros.

Ahora bien, la Lingüística actual, habituada a trabajar con sistemas, paradigmas, esquemas, etc., gobernadores de la actividad lingüística del individuo (y, para algunos, también de su actividad mental), al enfrentarse al texto y a su producción pone mucho menos el acento en la creatividad lingüística individual que en la potencialidad de moldes o «esquemas de discurso» que conformen los muy diversos tipos de discurso o realización linguística que pueden darse (y aquí las enumeraciones y clasificaciones son muy varias), y que gobiernen las elecciones lingüísticas de los hablantes en virtud de esos tipos de discurso: elección de unas estructuras u otras, de unos u otros órdenes (de palabras y de elementos de mayor rango), así como la constitución de determinados procedimientos lingüísticos peculiares. Parece constituirse así una complejísima «competencia», que atañe, pues, no sólo a la estructura fonológico-gramatical-léxica de la lengua sino a las condiciones de uso de la misma y a la construcción linguística que hallamos en ese uso. Si aplicamos esta perspectiva al análisis de los textos antiguos, en

${ }^{5}$ Véase H. H. Christmann, Filología idealista y lingüistica moderna, Madrid: Gredos, 1985. 
especial de los literarios (únicos de interés, según vimos, para la Sintaxis histórica), habremos de buscar esos moldes que conforman los diversos tipos de texto y las formas de lenguaje que los constituyen. Ello tiene un nombre y una larga tradición, que remonta, como tantas otras cosas, a los clásicos greco-latinos: la Retórica. De esta forma, direcciones de la Linguística moderna, tales como la teoría de la enunciación, la Lingüística del texto o el análisis del coloquio, acaban siendo, y ello es paradójico sólo en apariencia, algunos de los motivos que están tras el resurgimiento de la Retórica como elemento que ayuda a explicar el origen y la forma de los textos antiguos.

1. La Retórica ${ }^{6}$ constituía un complejo sistema de guías (casi un «repertorio de recetas») que iban desde la elección de los contenidos transmisibles y las partes de éstos (la inventio) a la ordenación de tales elementos (la dispositio) y sobre todo a la configuración linguiística de todo lo anterior (la elocutio). La elocutio disponía los tipos de lenguaje que podían utilizarse en función de los contenidos y las cualidades que debía poseerla forma lingüística (corrección o puritas, comprensibilidad o perspicuitas y adorno u ornatus); esta última es quizá la parte más conocida, pues es la que encierra los «tropos» y «figuras», que abarcan casi todas las posibilidades de actuación sobre la forma linguística, tanto en lo que se refiere a las dos caras del signo lingüístico («pensamiento»vs. «dicción») como a los distintos niveles de la estructura de la lengua (de lo fónico a lo gramatical, y aquí de la palabra a la oración y el período). El objetivo fundamental de la Retórica era conseguir la perfecta adecuación entre los caracteres y naturaleza del lenguaje utilizado y los caracteres y naturaleza del contenido de que se quería hablar (es el decoro, lo aptum). Como ha señalado con todo acierto Luisa LópezGrigera, de la Retórica se desprendía obligatoriamente que había «un estilo para cada materia, un estilo para cada género» ${ }^{\text {? }}$.

Naturalmente, la Sintaxis tenía un puesto de honor en este entramado teórico y prescriptivo: muchas de las llamadas «figuras» (en concreto, las denominadas in verbis coniunctis) se referían a fenómenos sintácticos, sin que, lógicamente, se estableciera ninguna separación entre lo que correspondería a la sintaxis estrictamente gramatical y a la sintaxis como ordenación del discurso, del texto en su conjunto. Por último, la Sintaxis volvía a tener un apartado especial final, en lo referente a la ordenación general del período, la compositio, que establecía las distintas conformaciones del texto (en general, circulares o paralelísticas).

Un sistema como éste no puede desdeñarse en absoluto: con la Retórica se elaboraban los textos, pues, en formas más o menos simplificadas o desarrolladas, la Retórica formaba parte del aprendizaje de todo hombre culto; y no sólo era un conjunto de formulaciones, sino que se traducía en constantes ejercicios que habituaban a los posibles futuros escritores a manejar y realizar sus principios. Por ello, la Retórica ha de estar, obligadamente, presente en nuestro análisis e interpretación de esos textos, si

\footnotetext{
${ }^{6}$ Véanse, como buenas introducciones modernas: H. Lausberg, Manual de retórica literaria (trad. de J. Pérez Riesco), 3 vols., 3ª reimpr., Madrid: Gredos, 1990; T. Albaladejo, Retórica, Madrid: Síntesis, 1989.

7 «La retórica como código de producción y de análisis literario», en G. Reyes (ed.), Teoría literaria en la actualidad, Madrid: Ed. El Arquero, 1989, págs. 135-166 (p. 150).
} 
queremos ir más allá de la constatación aislacionịsta de los diferentes fenómenos sintácticos que allí puedan encontrarse. Si queremos entender por qué están allí y por qué se disponen y ordenan en la forma en que lo hacen, habremos de topar con los viejos preceptos retóricos que, nos gusten o no, están detrás de todo ello.

Pero hay otro aspecto fundamental: es perfectamente posible que algunos, o todos los grandes cambios estilísticos habidos en la evolución de la lengua literaria (de una lengua o de varias, relacionadas por la historia) tengan que ver con cambios en las teorías retóricas dominantes en cada época. De esa forma intenta explicar López-Grigera el cambio tannotable de estilo entre el Marco Aurelio (1528) y el Relox de príncipes (1529) de fray Antonio de Guevara ${ }^{8}$ : el último se habría hecho eco del anticiceronianismo puesto en marcha por Erasmo, precisamente por esas fechas. Y, más aún, el gran cambio que se manifiesta desde finales del s. XVI hasta la elaboración de la lengua barroca (y que se refleja también en las dualidades estilísticas de fray Luis de León) ha sido, según la misma investigadora, puesto en marcha por el definitivo abandono del ciceronianismo y la elección de una retórica neo-estoica, con raíces en los retóricos bizantinos, muy difundidos en la cultura universitaria del XVI español, que acabará imponiendo un estilo básicamente de oraciones breves, dispuestas paralelísticamente (la culminación serán Quevedo o Gracián) 9 .

Naturalmente, con todo lo que venimos exponiendo, el mito del escritor como absoluto genio creador de su estilo ha de ir siendo arrinconado, como tantos otros mitos dañinos para la comprensión de la Historia que puso en circulación el Romanticismo. Ciertamente, con el aprendizaje de la misma Retórica hay autores deleznables y excelsos, pero los escritores excelsos antiguos (y aun muchos modernos) no hacen muchas veces sino llevar a la perfección estética lo que venía indicado en los tratados retóricos. Hemos de olvidar también la vieja afirmación de que «el estilo es el hombre»; en cierto modo sí lo es, pero es mucho más adecuado decir que «el estilo es el texto» (y los textos son muy variados, aún en cada autor).

Otro mito, éste de raíz más castiza, parece que va a tener también que ceder ante el avance de los estudios sobre textos antiguos en la dirección que venimos comentando. Del mismo modo que en el plano del contenido se ha venido hablando constantemente del «realismo» de la Literatura española, «realismo» que puede no ser también sino el efecto de una convención retórica (y no, por supuesto, una virtud de la raza) ${ }^{10}$, es muy

8 "Algunas precisiones sobre el estilo de Guevara», Studia Hispanica in honorem R. Lapesa, III, Madrid, 1975, págs. 299-315, y art. cit. en n. 7, p. 148; véase también, de la misma autora: «Retórica y Sintaxis en el siglo XVI: apuntes sobre un aspecto de la lengua literaria española», Actas del I Congreso Internacional de Historia de la Lengua Española, II, Madrid, 1988, págs. 1215-1224.

9 "La prosa de Quevedo y los sistemas elocutivo de su época», en Quevedo in Perspective. Proceedings from the Boston Quevedo Symposium: October 1980 (ed. by J. Iffland), Delawaré: Juan de la Cuesta, 1982, págs. 81-100; «Introducción al estudio de la retórica en el siglo XVI en España», NOVA TELLVS, 2, 1984, págs. 93-111.

${ }^{10}$ L. López-Grigera, «Sobre el realismo literario del Siglo de Oro», Actas del VIII Congreso de la Asociación Internacional de Hispanistas (1983), Madrid, 1986, págs. 201-209. 
probable que el otro «realismo», el de la forma linguiística, también deba ir olvidándose. Todos sabemos que el elogio más repetido para los más reputados autores españoles es el de «naturalidad», «sencillez» o cercanía a la lengua hablada, y en especial a la «popular». En uno de los Manuales de Historia de la Literatura española más utilizados en nuestras Universidades, el de J. L. Alborg ${ }^{11}$, he espigado caracterizaciones como las siguientes sobre algunos de los prosistas más relevantes del s. XVI: «prosa sencilla y elegante» (sobre el Lactancio de Alfonso de Valdés), «Como diálogo... es muy superior al Lactancio, más libre de retórica...» (Montesinos, sobre el Mercurio del mismo autor), «Precisión y sencillez sobre todo» (también Montesinos, sobre el Lazarillo), «Por grosero estilo hemos de entender estilo llano, lengua viva y natural, frase breve, sin digresiones, diálogo animado» (sobre el Lazarillo), «. . . la armonía, la serena belleza, la sencillezelegante...» (sobre fray Luis de León). Incluso, como es bien sabido, Menéndez Pidal llegó a afirmar que «Aun el estilo que más nos puede parecer artificioso, el de fray Antonio de Guevara, es, sin duda, el de la lengua hablada entonces, la hablada por un cortesano de extremada facilidad verbal. ... ${ }^{12}$.

Es imposible seguir compartiendo estas apreciaciones intuitivas. De hecho, hace ya tiempo que han surgido voces de investigadores con resonancias muy distintas: así, en 1957 M. Morreale ${ }^{13}$ fue señalando los moldes ciceronianos que sirvieron de pauta para la elaboración de la prosa de Alfonso de Valdés, y cómo en realidad sus procedimientos son muy semejantes a los de Guevara (ciertamente, lo más característico de Valdés es el paralelismo, rasgo éste no muy ciceroniano); más recientemente, en 1976 C. Barbolani ${ }^{14}$ ha señalado rasgos semejantes para Juan de Valdés; y en una Tesis Doctoral leída en 1990 en Deusto sobre El libro de Job de fray Luis de León, debida a Ramón Cao, se ha señalado cómo el cambio de estilo observable en las dos épocas de redacción del texto corresponde a un cambio de orientación en la Retórica de la época (la sustitución de Cicerón por Hermógenes). Por último, no hemos de olvidar que también «huir de la afectación» y «escribir como se habla» no son sino las recomendaciones más evidentes del magisterio retórico de Erasmo, aceptadas y defendidas con entusiasmo por los prosistas españoles seguidores suyos.

Por nuestra parte, creemos que no tiene mucho sentido utilizar la proximidad a la lengua hablada y popular como criterio de sublimidad estética, pues si desconocemos casi todo sobre cuáles son sus rasgos constitutivos hoy, mal podremos hablar de lo que se refiere a épocas anteriores; podremos pensar que tal o cual expresión es más «natural» que otra, pero mientras no delimitemos los rasgos distintivos de lo «natural», todo ello

${ }^{11}$ Historia de la Literatura Española, I, 2a ed., Madrid: Gredos, 1980 (las citas se hallan en las págs. 712, $715,791,819)$.

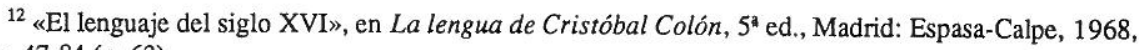
págs. 47-84 (p. 63).

13 «El Diálogo de las cosas ocurridas en Roma de Alfonso de Valdés. Apostillas formales», Boletín de la Real Academia Española, XXXVII, 1957, págs. 395-417.

14 «Los Diálogos de Juan de Valdés, ¿reflexión o improvisación?» Actas del Coloquio Interdisciplinar «Doce consideraciones sobre el mundo hispano-italiano en tiempos de Alfonso y Juan de Valdés» (1976), Roma, 1979, págs. 135-152. 
no pasará de ser un perjuicio lógicamente circular. Pero por otra parte, hemos de emprender un análisis lingüístico, y especialmente sintáctico, detallado de esos textos para ir delimitando sus estructuraciones peculiares, sus modos de construcción del periodo, el sentido del recurso y tales o cuales esquemas sintácticos. Sólo análisis de este tipo, del que aquí daremos unas breves muestras, podrán, por una parte, establecer el vínculo con las investigaciones de los especialistas en Retórica con el objeto de aclarar las intrincadas relaciones entre evolución de las formas de organización lingüística y evolución de las teorías retóricas; y por otra, establecer las invariantes y diferencias que, en una época determinada y en una sucesión de épocas, se van instituyendo en los textos producidos.

2. La lengua de Guevara ha sido una de las que más controversias ha suscitado entre los estudiosos (al fin, todo en Guevara ha generado interpretaciones contradictorias). Nadie duda de su artificio, y los medios con que éste se construye parecen también evidentes: para algunos, ello sería prueba de su escasa altura estética. Ahora bien, ese artificio ha sido calificada a la vez (aunque no por los mismos analistas, lógicamente) como «coloquial» y como alejado de toda naturalidad y ajeno, por tanto, a la «clasicidad» humaniśta, como medieval (heredero de la retórica de San Ildefonso) y como renacentista, e incluso como predecesor de estilos posteriores, como los del ensayismo de Montaigne, el euphuism inglés, o incluso la lengua cervantina ${ }^{15}$; en este sentido, Guevara, con sus paralelismos y antítesis, anunciaría el final del ciceronianismo triunfante en el primer Renacimiento.

Buen ejemplo de esta forma es su Menosprecio de corte y alabanza de aldea, publicada en 1539, unos diez años después, por tanto, del cambio de estilo observado por López-Grigera. Vamos a interesamos, de acuerdo con lo dicho más arriba, por los procedimientos sintácticos que configuran el armazón del estilo y la retórica guevarianas; ahí podremos ver si estamos ante un modo de construcción del texto ajeno a su tiempo histórico o propio de él.

El paralelismo en la disposición de los elementos sintácticos es continuo, y ha sido señalado, justamente, por todos los estudiosos del estilo guevariano. Ese paralelismo se logra mediante la acumulación yuxtapuesta de períodos, en cada uno de los cuales suele hallarse una estructura coordinada de dos elementos; a su vez, en cada elemento de los que forman la coordinación la disposición de los miembros oracionales es la misma (las funciones aparecen en el mismo orden), si bien en los lexemas que realizan alguna(s) de esas funciones puede darse una contraposición de tipo léxico, con lo que la antítesis es también evidente. A ese esquema responde, p. ej.:

${ }^{15}$ Véanse los estudios de López-Grigera y Menéndez Pidal citados en las notas 8 y 12; y además: $\mathrm{M}^{\mathrm{a}} \mathrm{R}$. Lida, «Fray Antonio de Guevara: Edad Media y Siglo de Oro español», Revista de Filología Hispánica, VII. 1945, págs. 346-388; y J. Marichal, «Sobre la originalidad renacentista en el estilo de Guevara» Nueva Revista de Filología Hispánica, IX, 2, 1955, págs. 113-128. 
«No ay estado en la iglesia de Dios tan absoluto en que uno no se pueda salvar, ni ay estado tan recogido a do no aya ocasiones para se perder» (p. 41) ${ }^{16}$,

en donde la correspondencia es perfecta, salvo que el complemento locativo en la iglesia de Dios no tiene por qué repetirse en el segundo elemento (sería un caso de zeugma ordinario), lo que sin embargo no ocurre ni con el verbo ni con su objeto; por otro lado, las secuencias tan + Adj. (con lexemas contrapuestos) no se desarrollan propiamente en estructuras consecutivas, sino que el segundo miembro es una relativa locativa, con una variatio gramatical (en que / a do: valor locativo de $a$ ); estas relativas presentan, sí, una estructura interna diferente, si bien ambas concluyen con infinitivo (con lo que la figura del homeoptoton está servida). Por último, es habitual que este tipo de afirmaciones guevarianas, «verdades eternas» o aforismos en los que el presente de indicativo es la regla, concluyan con una estructura causal pospuesta, estructura causal que no supone por lo general subordinación sintáctica por dos razones: en primer lugar, por situarse con frecuencia tras pausa fuerte, rompiéndose así el encadenamiento sintáctico del período, en lo que la Lingüística diacrónica anglosajona actual denomina afterthought, considerado uno de los motivos del cambio sintáctico ${ }^{17}$; en segundo lugar, por tratarse de «causales de la enunciación», según la terminología y caracterizaciones de R. Lapesa, F. Marcos Marín, etc. ${ }^{18}$, causales que no «dependen» de la aparente principal, sino de un verbo de «decir» implícito en el acto mismo de enunciación. En esa estructura, que, como vemos, no configura en absoluto ningún tipo de orden circular, puede insertarse de nuevo, al final, una secuencia paralela binaria, p. ej. en una oración de relativo:

«porque los officios, estados y preeminencias son como la rosa del campo de la qual haze su miel el abeja y aun su ponçoña la araña (ibid.)

Esa estructuración en secuencias yuxtapuestas con la misma estructura sintáctica y la misma disposición de sus elementos, ordenados a su vez en secuencias paralelas y léxicamente contrapuestas, llega al paroxismo en las ejemplificaciones concretas, o «casos», que desarrollan, también en estilo aforístico (con presente), lo afirmado en alguna enunciación anterior:

«El principe puedese salvar haziendo justizia y puede-

se condenar usando tiranía. El cavallero puedese

salvar peleando y puedese condenar robando. El ecle-

${ }^{16}$ Seguimos la edición de M. Martínez Burgos (Clásicos Castellanos, Madrid: Espasa-Calpe, 1967).

${ }^{17}$ David P. Lightfoot, Principles of Diachronic Syntax, Cambridge University Press, 1979, p. 385.

${ }^{18}$ Véanse: R. Lapesa, «Sobre dos tipos de subordinación causal», Estudios ofrecidos a E. Alarcos Llorach, 3, 1978, págs. 173-205; F. Marcos Marín, «A propósito de las oraciones causales», Cuadernos de Filologia, II, 1, 1979, págs. 167-171; L. Santos Río, «Reflexiones sobre la expresión de la causa en español», Studia Philologica Salmanticensia, 6, 1982, págs. 231-277; J. A. Bartol, Las oraciones causales en la Edad Media, Madrid: Paraninfo, 1988. 
siastico puedese salvar sirviendo su iglesia y puedese condenar entrando por simonia. El religioso puedese salvar contemplando y puedese condenar murmurando ...» (págs. 41-42)

En la disposición paralela de los elementos oracionales, como hemos podido observar en parte, no se atiende tanto a la identidad de funciones sintácticas reconocidas que desempeñen los diversos elementos (aunque también) cuanto a las funciones «informativas» o «discursivas»: es sobre ellas como se establece la correspondencia. Así, en el siguiente período:
«Entre los cretenses ley fue muy usada y guardada que si algún peregrino viniese de tierras extrañas a sus tierras propias no fuese nadie osado de pregun- tarle quien era, de donde era, que queria ni de donde venía, so pena que açotasen al que lo preguntava y desterrasen al que lo dixesse. El fin por que los antiguos hizieron estas leyes fue para quitar a los hombres el vicio de la curiosidad, es a saber, el querer saber las vidas agenas y no hazer caso de las suyas propias, como sea verdad que ninguno tenga su vida tan corregida, que no aya en ella que enmendar y aun que castigar. Lo mas en que ocupan los hombres el tiempo es en preguntar y pesquisar que hazen sus vezinos, en que entienden, de que viven, con quien tratan, a do van, a do entran y aun en que piensan; porque...» (p. 2)

observamos que inicia cada uno de los períodos yuxtapuestos entre sí lo que podemos llamar el elemento temático de la construcción, que en el primer caso es una construcción locativa no estricta, y en los otros dos podría considerarse el Sujeto de la construcción atributiva (cada uno de ellos desarrollado a su vez por sendas construcciones especificativas de relativo); por su parte, la primera construcción parece mostrar una cierta dislocación de orden, al anteponer un elemiento remático como ley (ese carácter remático encaja bien con la «esencialidad» provocada por la ausencia de artículo), que funciona como Sujeto de lo que podría considerarse construcción atributiva, pasiva o con fue de «existencia» («fue muy usada y guardada. .. ). Por otro lado, el elemento central significativamente de los tres períodos, su rema o «información nueva», es siempre de sintaxis mucho más compleja: en el primer caso, se trata de una construcción analizable como completiva de sustantivo (=«fue muy usada la ley (de) que... .» o menos probablemente como atributiva (=«la ley fue que...»), que consta a su vez de un clásico período circular'de prótasis y apódosis por medio de una estructura condicional; en el segundo período, el valor semántico del lexema Sujeto ( fin) ha hecho aparecer la preposición para ante un infinitivo cuya única función posible es la de atributo de fue; por último, en el tercer período también el hecho de que los infinitivos preguntar y pesquisar constituyan en la sustancia pensada el lugar «en que» ocupan los hombre el tiempo es 
lo que justifica la presencia de la preposición, reproducida por analogía de la oración de relativo, cuando esos infinitivos, en principio, parecerían cumplir también la función de atributos (se trataría de uno de los posibles desarrollos perifrásticos y enfáticos de una construcción «básica» como: «los hombres ocupan más el tiempo en. . .» / «en lo que más ocupan los hombres el tiempo es en. . .» / «lo más en que ocupan los hombres el tiempo es en. . .). Hay que destacar, finalmente, que cada uno de los tres períodos presenta una «coda», en la que el autor realiza algún comentario a propósito de lo anterior, con el valor de «causal de la enunciación» en los dos últimos casos y como una cierta "condición del enunciado» en el primer caso.

No es en Guevara tan habitual como el tipo sintáctico reseñado el que presenta la disposición «circular» (periodus, ambitus o circuitus la denominaron los latinos) en forma de prótasis-apódosis, disposición consistente por lo general en la secuencia subordinada-subordinante. El orden lineal prima, si bien puede producirse la anticipación catafórica del elemento subordinado:
«De Catón Censorino y del emperador Augusto y del gran Trajano y del buen Marco Aurelio dizen todos sus escritos que por esso fueron principes tan ilustres en sus hazañas y tan bien quistos en sus republicas, porque tenian siempre cabe si...» (págs. 16-17)

Sin embargo, la tensión que, según los retóricos, se conseguían por medio de la anteposición de la subordinada no es desconocida tampoco por Guevara, aunque éste suele relegarla a esas causales añadidas al final de sus períodos (como veremos, ambos hechos: configuración «circular» y arrinconamiento de ésta al final de un período, se presentarán, casi de la misma forma, en autores como Valdés o fray Luis):

«En menos yerros cayriamos y menos excesos cometeria-

mos si quisiessemos hazer lo que Sócrates hazia y

humillarnos a preguntar lo que el preguntava; porque

ya que los hombres no miran lo que hazen, devrian de

pesquisar lo que dellos los otros dizen (p. 5)

Pero también dicha ordenación puede hallarse, si bien es cierto que de forma menos habitual, constituyendo un período por sí sola. Es lo que hallamos en:

«Por absoluto que fuesse un cavallero y por dissoluto que fuesse un plebeyo, si quisiesse tener coraçon para dexarse avisar y tuviesse paciencia para consentirse corregir, es imposible que no enmendasse de vergüença lo que no dexa de cometer por consciencia» (ibid.),

donde encabezan la construcción dos secuencias yuxtapuestas, concesiva la primera y condicional la segunda, bimembrada cada una de ellas (y con una evidente igualdad de desinencia verbal en todos los casos), y con perfecta equiparación entre los 
elementos constitutivos de cada brazo. Al mismo tiempo, en la «principal» la oración de relativo sustantiva que viene a constituir el Objeto Directo de la completiva Sujeto reitera, mediante contraste, los complementos preposicionales de carácter modal (de vergüença / por consciencia), aparte del contraste que puede establecerse entre el significado léxico de los núcleos verbales.

No es difícil, pues, caracterizar el modo de construcción guevariano. Pero esos paralelismos sintácticos combinados con antítesis significativa no son nada extraños en la historia del español. Los ejemplos pueden ir, en textos espigados al azar, desde Alfonso X: «Qui sabe parar mientes en qual sazon esta fuerça viene de todas / \& sabe obrar en ello como conuiene / \& quando, aquel puede auer deste saber lo que quisiere / \& alcançar la uerdat dello» (Libro del Saber de Astrología, ms. Cód. Complutense) a Quevedo: «No hay dichoso sin envidia de muchos, ni hay desdichado sin desprecio de todos» (La hora de todos). Ciertamente, las diferencias de época y las alegadas tantas veces de calidad estética no deberían hacernos olvidar que nos hallamos ante idéntico uso de procedimientos sintácticos.

3. Vamos a enfrentarnos ahora con un texto casi coetáneo, el Diálogo de Mercurio y Carón, compuesto por Alfonso de Valdés, muy probablemente en torno a 1529. De este texto, cuya lengua, aparte de lo dicho más arriba, ha sido caracterizada por un moderno editor, J. F. Montesinos ${ }^{19}$, como «matizada y vivaz, que se adorna de despojos clásicos sin perder por ello una cierta familiaridad ligera, grata siempre a españoles (. . .) ágil, dúctil, apta. . .», vamos a intentar entresacar algunos aspectos fundamentales en la organización sintáctica, en especial de fragmentos en que el monólogo de alguno de los personajes adquiere un tono discursivo cercano al «ensayismo» de Guevara (los trozos de diálogo rápido aligeran, por lógica necesidad, la estructura sintáctica: sobre ellos habrá que volver en otra ocasión). Veremos si el tipo de texto condiciona la estructuración sintáctica y si los procedimientos son semejantes a los de Guevara.

Un rasgo que apenas habíamos visto hasta ahora, y que en Valdés parece recurrente (pero veremos que no sólo en él), es la acumulación de circunstancias previas, manifestadas en distintos tipos de subordinadas «circunstanciales», antes de la «principal». Nos hallamos, en cierto modo, ante una nueva forma de orden subordinadasubordinante, pero no es éste el tipo de organización circular en el que se aduce en primer lugar un elemento problemático que descarga su tensión significativa en el segundo miembro, el sintácticamente «principal». Podemos ver tal situación en casos como los siguientes:

«Enojado comigo mesmo de ver en toda parte tanta comupción, con desseo de ver algun pueblo que por razon natural viviesse, acordandome de los que Jesu Christo instituyó y haviendo visto aquellas sanctissimas leyes que con tanto amor tan encomendadas les dexo, determine de buscar. . .» (págs. 11-12),

${ }^{19}$ Clásicos Castellanos, Madrid: Espasa-Calpe, 5ª ed. 1971. 
donde se siguen, en serie internamente yuxtapuesta, pero con una progresión significativa interna clara de establecer a partir de los significados de cada uno de esos elementos, los siguientes miembros: participio concertado con el Sujeto (manifestador de la situación anímica de éste), Sintagma preposicional de idéntico valor (también en referencia predicativa al Sujeto), y dos gerundios que introducen una cierta justificación ( $¿$ de orden causal?) respecto a lo que se va a enunciar en la principal: de ellos el segundo aparece en forma compuesta, lo que intensifica el carácter «previo», a la «principal», que presentan todas estas determinaciones. Si bien en este inicio de período la función sintáctica (y significadora) de estos elementos es la misma, no nos hallamos tampoco ante elementos ordenados paralelísticamente, aunque las estructuras sintácticas mantienen diversos puntos en común; entre ellos podríamos señalar que los tres últimos miembros concluyen en construcciones relativas (no idénticas en tipo entre sí), en todas las cuales el verbo se halla al final, lo que no deja de ser una reminiscencia de la sintaxis latina, y a también de la Retórica antigua.

Una disposición más paralela, sobre la base de acumular circunstancias ante el miembro sintáctico «principal», la hallamos en:

«Como yo esto oy, aunque no diesse entero credito a las palabras de Alastor, todavia, por saber si era verdad, atine hazia Europa (...) y llegado alla, por poderlo mejor comprehender, subime a la primera spera...» (p. 12)

donde, como podemos observar, el período viene integrado por dos secuencias de Circunstanciales + Principal (con el rasgo añadido de que ambas Principales vienen constituidas por verbos de movimiento): en esas «circunstanciales» se integran, en el primer caso, temporal, concesiva y final, y en el segundo, construcción concertada «temporal» y final.

Pero donde el paralelismo valdesiano estalla en toda su amplitud es en el párrafo en que Mercurio se dedica a contraponer lo que ordena la auténtica doctrina de Cristo y lo que es la práctica habitual de los pueblos que a símismos se llaman cristianos. Nos vamos a encontrar nuevamente una serie de períodos enlazados entre sí por yuxtaposición (se trata de una enumeración), dentro de los cuales se va a reproducir el mismo esquema sintáctico. La situación es conocida: sólo que Valdés introduce pequeñas variantes internas, con lo que el resultado final es menos monótono que las parrafadas de Guevara. De esta manera, en el párrafo que sigue inmediatamente el reseñado arriba, al verbo principal hallé, colocado ya en primer lugar (va coordinado a lo anterior), sigue una locativa, incluida ya en la estructura completiva de Objeto Directo, y que viene a constituir la antítesis de lo dicho en esa completiva (si bien aquí tampoco las estructuras son paralelas por entero); a continuación, la primera variación: la locativa, precede a la secuencia hallé + Completiva (la contraposición, por lo demás, continúa dándose), completiva que viene constituida por una larga serie de estructuras yuxtapuestas 
paralelas (con zeugma continuo del verbo: «hallé que unos la ponen en vestidos, otros en diferencias de manjares, otros en cuentas. . .»), que terminan con una coordinada copulativa a hallé, que viene a ser la conclusión que saca el locutor de la anterior enumeración (conclusión que se intensifica al rematar todo el período con la ilación, más que subordinación, consecutiva: «... de manera que muy poquitos eran los que. . .»). El siguiente período vuelve a repetir la ordenación del anterior: Locativa/Principal + Completiva, pero ahora el verbo «principal» es vi, que acababa de aparecer en el período anterior coordinado a hallé. Esta alternancia, con una disposición sintáctica distinta, se va a convertir en el eje de la construcción paralela que el locutor desarrolla a continuación:

«Hallava en la doctria chistiana ser verdadero sabio el que sabía abraçar la doctrina de Jesu Christo, y $v i$ que tenían por nescio al que a ella se allegava y por sabio al que della se apartava. Más adelante hallava ser aquel verdaderamente poderoso que podía domar y sojuzgar sus apetitos y passiones, y $v i$ que no tenían por poderoso sino al que podía hazer mucho mal, aunque por otra parte de todos los vicios se dexasse vencer. Hallava ser bienaventurado el que, menospreciadas las cosas del mundo, todo su spiritu tiene puesto con Dios, y $v i$ tener entre ellos por bienaventurado al que, allegando muchas cosas mundanas, ningún respecto mundano tiene a Dios» (págs. 13-14)

Aquí el paralelismo abarca ya todos los aspectos de la construcción sintáctica, en una forma idéntica en principio a la señalada para otros textos. Así, encontramos que todos los períodos se organizan sobre la base de una coordinación entre dos verbos, los mismos (hallar y ver), cuyo contraste aspectual es recurrente también (si bien más tarde aparecerá la igualación hallava = veía), y supone el choque brutal (el vi perfectivo) que sobre el conocimiento previo del locutor ( hallava imperfectivo) tiene la constatación de la triste realidad, tan opuesta a lo soñado. Al mismo tiempo, cada uno de esos verbos lleva una complementación, de infinitivo no concertado par hallar, y de completiva con $q u e$ para $v i$, hasta el último período, en que $v i$ adquiere también la complementación de infinitivo. Por otra parte, también esas estructuras subordinadas son paralelas: ser+Sujeto consistente en una estructura sustantiva de relativo de "generalización» (para el complemento de hallar), y tener (= «considerar»)+Objeto Directo, consistente también en una estructura relativa del mismo tipo. Por último, en el período final las secuencias el que, Sujeto y Objeto Directo respectivamente, llevan inmediatas, antes del núcleo de su construcción, construcciones semejantes en forma sintáctica y, sobre todo, iguales en significación (acciones previas): participio absoluto el primero («menospreciadas. ..») y gerundio concertado el segundo («allegando...»).

El gusto por la variatio, sin embargo, es más notable en Valdés, y, lo que es más digno de observar, los nuevos elementos que van tomando el relevo (pues la estructura básica sigue siendo idéntica: cada período consta de dos miembros fundamentales, 
coordinados sintácticamente, pero contrapuestos en significado) van incorporándose progresivamente, a partir de una primera entrada. Así, el esquema que hemos visto hasta ahora se rompe, parcialmente, en un momento:

«Quiso Jesu Christo que no jurassen, mas que toviessen

tanta sinceridad, que con su simple palabra fuessen

creídos, y veíalos a cada passo jurar...» (p. 14)

Tras una vuelta al esquema primero, pronto se repite este nuevo, pero con igualdad de tiempos en los dos miembros, ahora perfectivos, mostrando tanto la voluntad decidida de Cristo como la impresión recibida por Mercurio:

"Quiso Jesu Christo que no se enojassen unos con otros ni se dixessen malas palabras, mas que procurassen de hazer bien a los que les hiziessen $\mathrm{mal}^{20}$, y vilos no solamente dezirse unos a otros injurias, mas matarse y lisiarse como brutos animales y tener por muy grande affrenta no vengarse de la injuria recibida» (p.15)

Y por último aparece el nuevo esquema desarrollado por el locutor a partir de las variaciones vistas, en donde se contrapone igualmente lo dicho por Cristo y lo realizado por los cristianos, pero expuesto todo ello con esos Sujetos, en $3^{\mathrm{a}}$ persona, excluyéndose, pues, toda presencia del locutor; en este nuevo esquema surge también la variedad, en especial en el primer elemento, el «decir» de Cristo:
«Dizeles Jesu Christo que den sus limosnas secretamente
(. . .) y ellos solamente hazen secreto las malas obras
(...)Dizeles Christo que no daña el anima lo que entra por la boca (...) y ellos en el comer muy supers- ticiosos ${ }^{21}(.$. ) Christo loa la pobreza (. . .) y ellos huyen la pobreza (...) Reprehende Christo a los que procuran los primeros asientos (...) y ellos con tanta ambición los buscan. . .» (ibid.)

El final de esta larga tirada viene señalado explícitamente: el locutor utiliza, por una parte, un adverbio con función textual ilativa (tras la copulativa), y a continuación un sintagma de origen consecutivo, pero desligado ya de cualquier función sintáctica subordinante y circunscrito al establecimiento de la cohesión textual; ambas secuencias constituyen las dos fases de la conclusión a partir de lo anterior, lo que viene reforzado por el uso, en estas oraciones, de los mismos verbos empleados en la tirada de miembros alternativos ( vi y hallé), sólo que en orden inverso al que habían traído:

${ }^{20}$ Obsérvese la repetición de las secuencias binarias, con frecuencia también paralslísticas.

${ }^{21}$ Obsérvese el carácter de insistencia enfática aportada por la construcción nominal reiterada. 
"Y finalmente, los vi a todos tan agenos de aquella paz y charidad que Jesu Christo les encomendo, dexandosela por señal con que los suyos fuesen conoscidos, que en todo el mundo junto no ay tantas discordias ni tan cruel guerra como en aquel rinconcillo que ellos ocupan. De manera que cotejando en estas y en otras muchas cosas (...) hallé que. . .» (p. 16)

No hallamos, pues, ante una prosa conscientemente elaborada y, por supuesto, no menos artificiosa que la de otros escritores tradicional (y tópicamente) tenidos por tales. La organización sintáctica del período se adecua por entero al contenido que se quiere transmitir. Pero, lo que a nosotros más nos interesa, los procedimientos sintácticos escogidos para dicha complejidad sintáctica, en un intento de manifestar en el fondo y en la forma un pensamiento que se mueve por bipolaridades, no difieren gran cosa de los vistos en otros textos: yuxtaposición entre los períodos, y subordinaciones no excesivamente complejas en las partes centrales de esos miembros (completivas en primer lugar, y relativas que desarrollan algunos de los elementos concretos). Sólo al final de esos miembros, cuando se intenta dar alguna matización, justificación, etc., aparecen otros tipos de subordinación: entre ellos es muy habitual la presencia de consecutivas que, de este modo, vienen a ser la conclusión del razonamiento.

4. Parecería que la lengua del hermano de Alfonso, Juan de Valdés, debería mostrar características radicalmente distintas, dado que desde la definitiva atribución del Diálogo de la Lengua viene siendo considerado el máximo paladín de la espontaneidad y naturalidad lingüísticas como ideales elocutivos: «estilo cuidado pero en apariencia natural y sin afectación», tal como lo define López-Grigera ${ }^{23}$. Sin embargo, no convendría olvidar que la frase emblemática de dicha actitud: «Para deziros la verdad, muy pocas cosas observo, porque el estilo que tengo me es natural, y sin afectación ninguna escrivo como hablo» muestra rasgos tales como la colocación retórica del verbo al final de la frase (en «muy pocas cosas observo»y, precisamente, en «... escrivo como hablo»), además del posible quiasmo en las dos últimas frases, en las que se observa una secuencia cruzada Verbo + expresión modal (no propiamente complemento de ese tipo) / Complemento modal + Verbo, en la que ambos elementos «modales», redundando en el mismo contenido (la «naturalidad») emplean lexemas contrapuestos (natural / afectación), manifestadores del ideal y de lo nefando en la ideología estilística de la época.

La situación, pues, no es tan nítida. La prosa de Juan de Valdés puede ser también artificiosa, si bien ese artificio es mucho más medido que el de Guevara o el de su hermano Alfonso; por otra parte, los recursos utilizados no son exactamente los mismos: el paralelismo no surge de forma tan arrolladora y omnipresente, pero hay una constante y buscada trabazón de los períodos y los elementos de éstos, en la que a veces se recurre a procedimientos ya conocidos.

${ }^{23}$ «Estela delerasmismo en las teorfas de la lengua y delestiloen la España del siglo XVI», en Elerasmismo en España, Santander: Biblioteca Menéndez Pelayo, 1986, págs. $491-500$ (p.494). 
Así, en los inicios del diálogo el personaje Marcio toma la palabra para narrar los antecedentes de la petición que hacen a Valdés (explicarles esos «punticos y primorcicos de lengua vulgar»), el desconcierto que les habían producido algunos rasgos de la lengua valdesiana, $\mathrm{y}$, también, para mover favorablemente el espíritu de Valdés. No es una captatio benevolentiae en sentido estricto, pero participa en cierto modo de las intenciones significativas de ésta. Ello puede explicamos que el autor haya recurrido a un modo de organización sintáctica relativamente complejo.

En principio, la construcción no es ni circular ni paralelística sino continua; sería un modo de oratio perpetua, pero no sólo mediante la coordinación, sino por encadenamiento sintáctico de los elementos que se suceden. Eso sí, desde el principio se observa el gusto por las parejas de elementos («conservaríades y entretemíades»), que más tarde se convertirán en tríadas («descanso, passatiempo y plazer»), en una excelente manifestación de lo que Dámaso Alonso bautizó con la felicísima expresión de sintagmas no progresivos ${ }^{24}$. Ahora bien, el que el paralelismo no sea tan evidente no quiere decir que no exista. Los dos primeros períodos:

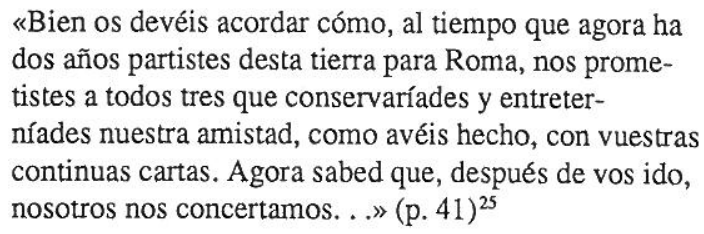

muestran una estructuración semejante de Verbo «mental» + Completiva (la primera, interrogativa indirecta), con la que se alude a la información ya conocida por Valdés ( Bien os devéis acordar...») y a la que se le va a suministrar en ese momento («Agora sabed que...»). Igualmente, una vez iniciada la completiva, se introducen las ubicaciones temporales que les corresponden («al tiempo que (. . .) después de vos ido»), realizadas, sí, con esquemas sintácticos distintos. A continuación, la completiva de sabed engarza una nueva completiva, anunciada catafóricamente («... nos concertamos desta manera, que. . .»); a concertamos se encadenan dos coordinadas copulativas que suponen una secuencia progresiva, en cuanto que expresan la realización del propósito ( y esto avemos hecho siempre assí» y el placer obtenido ( y con ello avemos tomado mucho descanso. ..»). Del mismo modo que habíamos observado en Guevara o en su hermano Alfonso, tras la enunciación fundamental se suceden las justificaciones, en este caso encadenadas: un primer porque enlazado a «. . . avemos tomado mucho descanso, passatiempo y plazer...», y el segundo subordinado al último miembro de este subperíodo causal («teníamos sobre qué hablar y contender, porque el señor Pacheco. ..»). La primera de las causales con porque (en este caso, más bien «causal del enunciado» anterior») ofrece en su interior una estructura triple, con disposición, ahora

${ }^{24}$ «Sintagmas no progresivos y pluralidades», en D. Alonso y C. Bousoño, Seis calas en la expresión literaria española, $4^{\mathrm{a}}$ ed., Madrid: Gredos, 1979, págs. 21-41.

${ }^{25}$ Seguimos la edición de J. M. Lope Blanch (Madrid: Castalia, 1976). 
sí, paralela de los miembros, un Complemento instrumental (con + SN en los dos primeros casos, y gerundio en el último) precediendo a cada uno de los verbos:

«... porque con la lición refrescávamos en nuestros ánimos la memoria del amigo ausente, y con los chistes y donaires, de que continuamente vuestras cartas venían adomadas, teníamos de qué reir y con qué holgar, y notando con atención los primores y delicadezas que guardávades y usávades en vuestro escrivir castellano, teníamos sobre qué hablar y contender» (p. 41)

Otro rasgo que va a aparecer inmediatamente en el discurso de Marcio, y que habíamos podido señalar a propósito del de Mercurio, es el amontonamiento de expresiones circunstanciales ante la oración principal. En este caso, en el segundo elemento causal con porque, dichas expresiones tienen todas, independientemente de sus diversas formas sintácticas, función justificadora, causal, refiriéndose, parece, a la justificación que Marcio quiere dar a las disputas lingüísticas que en su momento habían tenido las tres interlocutores de Valdés:
«. . . porque el señor Pacheco, como hombre nacido y criado en España, presumiendo saber la lengua tan bien como otro, y yo como curioso della, desseando saberla assí bien escrivir como la sé hablar., y el señor Corio- lano, como buen cortesano, quiriendo del todo entender- la (porque, como veis, ya en Italia assí entre damas como entre cavalleros se tiene por gentiliza y galanía saber hablar castellano), siempre hallávamos algo ...» (ibid.)

Cada uno de esos tres «amontonamientos» sigue una disposición muy parecida, paralela en el fondo: construcción con como indicadora de la situación relativa que ocupa cada personaje, y construcción de gerundio manifestadora de las distintas motivaciones de cada uno. El resto del parlamento de Marcio manifiesta una forma relativamente más lineal, si bien la trabazón sintáctica de un párrafo que intenta ser una petición justificada, razonable y atendible por alguien tan suspicaz como Valdés no deja de ser admirable.

Sería absurdo insinuar que la «artificiosidad» sintáctica que hemos intentado poner de manifiesto resta algo al nivel estético en que se había venido colocando esta prosa: todo lo contrario. Pero lo que sí parece fuera de razón es identificar la belleza de la prosa valdesiana con una supuesta familiaridad natural. Utiliza, sí, los procedimientos sintácticos de forma más sutil que Guevara, e incluso que su hermano Alfonso. Pero los procedimientos sintácticos son, básicamente, los mismos, y la guía retórica no debía diferir en exceso; no hemos hallado, por ejemplo en esta larga parrafada, tan elaborada, ningún período «circular» al modo ciceroniano. 
5. La prosa de fray Luis de León ha sido entendida habitualmente como una primera inflexión hacia un modo distinto de construir la lengua literaria. Es aún un «clásico», pero su «trabajada selección», según la expresión de Menéndez Pidal, apunta ya a nuevas orientaciones. De todas formas, la visión habitual que se tiene sobre fray Luis ha seguido siendo, con más o menos matices, la que sentó el mismo Menéndez Pidal: «Así, a pesar del gran estudio y compostura, la lengua de fray Luis se mantiene aún dentro del principio de naturalidad» ${ }^{26}$.

Y sin embargo la situación vuelve a no encajar con tanta nitidez como se esperaría de estas palabras. En De los Nombres de Cristo ${ }^{27}$, quizá su mejor producción en prosa, hemos hallado algunos de los párrafos más complejos y elaborados de todos lo que venimos analizando. En ellos fray Luis alterna períodos paralelos y otros circulares, y desarrolla incluso en éstos los paralelismos de una forma compleja, sin que el armazón quede tan evidente (y burdo, por tanto) como en Guevara. Pero, nuevamente, el hilo conductor de la estructuración sintáctica sigue siendo el mismo: no olvidemos que para algunos en fray Luis se consuma definitivamente el abandono de los moldes retóricos ciceronianos, que tampoco eran dominantes en los autores vistos.

Fray Luis parece tener una construcción sintáctica favorita: la comparación (assí) como... assí, en donde se establece en primer lugar el término de comparación, a modo de «prótasis», y como segundo miembro del período, a modo de «apódosis», el término «real»; en uno y otro miembros fray Luis desarrolla minuciosamente los rasgos que sirven para establecer la comparación, primero en el comparante, y luego con su correspondencia en el comparado. En la p. 37 de la edición utilizada de Nombres hay dos períodos seguidos construidos de la misma manera:

«Porque assí como en el árbol la rayz no se hizo para sí (. . .) assi por la misma manera estos cielos estendidos que vemos...» «Y assí como el fructo. . . contiene en sí (. . .) assí también Cristo. . . lo contiene todo en sí»

Observemos, sin embargo, que cada uno de los miembros de las comparaciones presenta estructuras divergentes, pero que en último término podrían equipararse, pues los contenidos son perfectamente contrastables. Así, en la primera comparación, el primer miembro consta de una frase bimembrada por medio de una coordinación adversativa excluyente, y en ellas se dan una larga sucesión de Sujetos sintácticos (unidos con procedimientos variados) en los que se desgranan las diversas partes del elemento comparante, el «árbol»:

«... assí como en el árbol la rayz no se hizo para

sí, ni menos el tronco, que nasce y se sustenta sobre ella, sino lo uno y lo otro, juntamente con las ramas y la flor y la hoja y todo lo demás que el árbol

${ }^{26}$ «El lenguaje del siglo XVI», págs. 78-80.

${ }^{27}$ Utilizamos la edición publicada en Madrid: Espasa-Calpe (Col. Austral). 
produze, se ordena y endereza para el fructo que del sale, que es el fin y como remate suyo... .»

En el segundo miembro, la enumeración de elementos que podría hacerse corresponder a los del árbol (los elementos del Universo están creados para mayor gloria de Dios, fruto supremo) funciona como serie de Objeto directos antepuestos, «tematizados», como lo muestra la reduplicación pronominal que recoge directamente la expresión con que se resume todo lo dicho:

«. . assí por la misma manera estos cielos estendidos que vemos, y las estrellas que en ellos dan resplandor, y entre todas ellas esta fuente de claridad y de luz que todo Io alumbra, redonda y bellísima; la tierra pintada con flores y las aguas pobladas de peces; los animales y los hombres, y este universo todo, cuan grande y cuan hermoso es, lo hizo Dios, para fin de hazer hombres a su Hijo, y produzir a luz este único y divino fructo, que es Cristo, que con verdad le podemos llamar el parto común y general de todas las cosas»

Como vemos, la variedad de engarces sintácticos es aún menor que en los Valdés (y semejante a la de Guevara): dentro de la estructura comparativa general los elementos se reúnen fundamentalmente por acumulación (yuxtaposición y coordinación combinadas).

Grado más alto de paralelismo sintáctico presenta la comparación que sigue inmediatamente; en sus dos miembros la disposición de los elementos es idéntica: Sujeto en primer lugar (son los «temas», los elementos sobre los que se realiza la comparación, los pilares del período), estructuras relativas que apuntan al origen respectivo («para cuyo nacimiento. ...»), verbo principal idéntico (contiene) y desarrollos en forma de complementos directos, y en el segundo miembro de verbos cuasisinónimos, al menos en este discurso, coordinados con el «principal»:

«Y assí como el fructo, para cuyo nascimiento se hizo en el árbol la firmeza del tronco y la hermosura de la flor, y el verdor y frescor de las hojas, nascido contiene en sí y en su virtud todo aquello que para él se ordenava en el árbol, o por mejor dezir, al árbol todo contiene; assí también Cristo, para cuyo nascimiento crió primero Dios las rayces firmes y hondas de los elementos, y levantó sobre ellas después esta grandeza del mundo con tanta variedad, como si dixéssemos, de ramas y hojas, lo contiene todo en sí y lo abarca y se resume en él, y, como dize sant Pablo, se recapitula todo lo no criado y criado, lo humano y lo divino, lo natural y lo gracioso» 
Una diferencia digna de señalar: en las respectivas oraciones de relativo referidas a los Sujetos la primera tiene un predicado de significación «media»: «se hizo en el árbol la firmeza del tronco. ..», pero en la segunda el predicado es «activo» y su Sujeto es Dios: «crió primero Dios las rayces. ..». Por otro lado, en la primera oración de relativo sólo hay un predicado, y varios Sujetos encadenados por coordinación copulativa reiterada(lo que, como se sabe, proporciona claro énfasis); pero en la segunda encontramos dos ( crió y levantó), bimembración que se repite en las estructuras de los complementos («rayces firmes y hondas», «con tanta variedad. . . de ramas y hojas»). Al final del período, las tres parejas de sintagmas coordinados subsumen la unidad de todo lo que en el mundo es (y en él, como vemos, todo es binario).

Pero no es éste el único modo de organización de los períodos en fray Luis. Otro, muy querido por él, es la disposición enumerativa (que se presta a desarrollos paralelísticos) en la forma: «Lo primero... . Lo segundo...». Sin embargo, nos interesa más en este momento el ocasional recurso al período circular, que, al igual que en otros textos analizados, se encuentra en una estructura causal que continúa a las comparaciones antes analizadas, y que constituye nuevamente una «causal de la enunciación», lo cual muestra, entre otras cosas, la inexistencia, ya, de subordinación sintáctica:

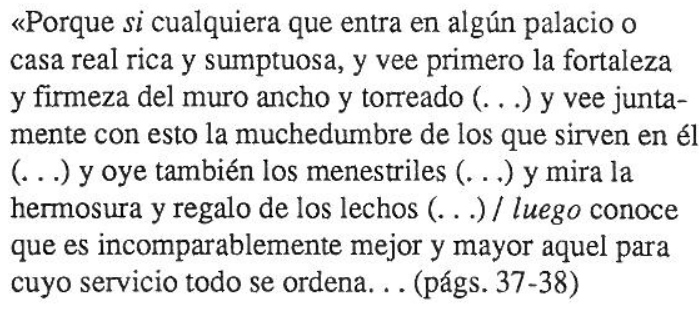

La ordenación es ahora, sí, claramente circular: la prótasis, en este caso una condicional, precede a la apódosis: la acumulación de elementos en la prótasis hace que los núcleos de una y otra queden muy alejados, con lo cual la tensión significativa que este modo de ordenación del discurso suscita se incrementa aquí hasta grados extraordinarios. En efecto, la prótasis consta de varios núcleos (vee (2 veces), oye, mira, variaciones en realidad de una misma significación de "percibir»), cada uno de los cuales presenta una más o menos larga serie de complementos (Objeto directos) en los que parece de rigor la estructuración en parejas, de sustantivos pero también de adjetivos y otros:
«. . .la fortaleza y firmeza del muro ancho y torrea-
do... y las galerías y los chapiteles... y luego
la entrada alta y adornada... y después los zagua-
nes y patios grandes y diferentes...».

aunque en algún caso se llega a la acumulación ternaria («y la diversidad y muchedumbre y orden de los aposentos. ..», y aun cuaternaria ("y con el jaspe y el pórfiro y el marfil y el oro que luze por los suelos...»). 
Ahora bien, este período circular de prótasis y apódosis condicionada constituye a su vez el primer elemento de una comparación formulada, como hemos visto, de manera algo diferente. No sólo el sentido de lo que se está diciendo nos inclina a ver que estamos nuevamente ante algo muy próximo a la alegoría, sino que a continuación todo lo dicho es recogido por el adverbio assí, característico introductor del elemento «comparado» en estas estructuras tan gratas a fray Luis:

\section{«.. . assí devemos nosotros también entender que si es hermosa y admirable esta vista de la tierra y del cielo, es sin ningún término muy más hermoso y maravilloso aquel por cuyo fin se crió» (p. 38),}

donde, como puede observarse, lo comparado incluye también un pequeño período circular de prótasis condicional y apódosis condicionada, con lo cual se refuerza finalmente el paralelismo con la organización sintáctica del comparante (la diferencia sólo radicaría en la brevedad de esta segunda secuencia condicional). Como vemos, pues, incluso aquí la disposición que sale triunfante es la paralelística, y los mecanismos sintácticos son los mismos que hemos venido analizando: no muy variados, ciertamente (los tipos de estructuras sintácticas manejadas no llegan a la media docena), pero combinados en formas complejas y, sobre todo, acumulantes. Las diferencias estéticas habrán de radicar, pues, en otros aspectos: los diversos estilos comparten la misma armazón.

6. Si, finalmente, dirigimos nuestra mirada a esa joya que es el Lazarillo de Tormes la impresión primera que sacamos es muy diferente. En él parecen estar en buena parte ausentes estos artificios: su prosa se ha calificado como de «estilo humilde», o también como de «estilos mezclados», lo cual sería lo característico de ls prosa moderna, y el Lazarillo lo compartiría, por ejemplo, con el Quijote ${ }^{28}$.

En efecto, un estilo semejante, aunque mucho más discreto, a los vistos hasta ahora casi sólo se halla en el Prólogo, supuestamente escrito por el mismo Lázaro de Tormes y lleno, como han señalado los estudiosos, de las tópicos propios de tales exordios en la Retórica de su tiempo, que el autor utiliza con una sabia ironía. Así, el comienzo se inscribe en una prosa encadenada, progresiva, por medio de la sucesión de principal y subordinada completiva, a lo que sigue una causal justificadora de la aserción de lo anterior (disposición esta última que conocemos ya); todo el conjunto se va bifurcando en secuencias binarias ( $y$, a veces, cada miembro en una nueva secuencia binaria), cuyos componentes establecen una cierta contraposición mutua en lo que hace a sus significaciones léxicas:

«Yo por bien tengo que cosas / tan señaladas y por ventura nunca / vistas ni oídas // /vengan a noticia de muchos y no se entierren en la supultura del olvido/, 
pues podría ser que / alguno que las lea halle algo que le agrade, y a los que no ahondaren tanto los deleite/. Y a este propósito dice Plinio que no hay libro, por malo que sea, que no tenga alguna cosa buena» ${ }^{29}$

El encadenamiento de los períodos lo hace Lázaro de Tormes (y su autor) con un procedimiento que había tenido su auge en la Edad Media como característica de la oratio perpetua del relato histórico: la presencia de la copulativa al inicio de cada parte de la construcción. Lázaro recurre a ese polisíndeton, nunca desaparecido de la expresión del español, en un contexto distinto (está exponiendo y razonando: ahí Alfonso X ya había desterrado las secuencias $E t$. . et ...): ¿es a lo más que llega el habla artificiosa y retórica coetánea? Ahora bien, que Lázaro es capaz de complejidad y variedad sintácticas superiores a las vistas en otros textos, pese a su aparente sencillez, queda claro en uno de estos períodos:
"Y esto para (en) que ninguna cosa se debría romper, ni echar a malo, si muy detestable no fuese, sino que a todos se comunicase, mayormente siendo sin perjuicio y pudiendo sacar della algún fructo; porque, si así no fuese, muy pocos escribirían para uno solo, pues no se hace sin trabajo, y quieren, ya que lo pasan, ser recompensados, no con dineros, mas con que vean y lean sus obras, y si hay de qué, se las alaben» (p. 88)

El período consta, tras la principal, de la completiva (con dos infinitivos dependientes, coordinados en negación) y en relación con ésta una condicional, aquí pospuesta (pero con verbo al final de la frase); la coordinada (¿० subordinada?) adversativa con sino que va unida al verbo de la completiva (debría romper), y es ampliada por dos gerundios destacados por el adverbio mayormente, que introducen una cierta justificación de índole causal a lo dicho por comunicase; de un modo también muy conocido, aparece una «causal de la enunciación» con porque, que consiste en un período de prótasis condicional y apódosis condicionada, a lo que sigue una nueva causal con pues (también motivación adicional, afterthought), en la que se coordinan tres elementos, de los cuales los dos últimos aparecen interferidos por causal la penúltima («yaque...»)y por complementos instrumentales bimembres en adversación excluyente («no con... mas con. . .»), y la última por condicional («si hay. . .). Se trata de una secuencia lineal y progresiva, pero altamente elaborada y engarzada en sus componentes internos.

Como vemos, los paralelismos, los períodos circulares, las disposiciones simétricas tienen en Lazarillo escasa representación, y si aparecen es en forma absolutamente morigerada: el estilo «humilde» de un pregonero no se podía esperar otra cosa, pero la elegancia de su autor nos lo ha dado en una forma insuperable. Las máximas acumula-

${ }^{29}$ Utilizamos la edición de A. Blecua (Madrid: Castalia, 1972). 
ciones de elementos que he hallado en la obra se dan en esos trozos en que, con extrema sabiduría, el autor se demora en la narración de una catástrofe que el lector adivina y que, angustiadamente, espera ver estallar:

«Y luego otro día, teniendo ya rezumando mi jarro como solía, no pensando el daño que me estaba aparejado ni que el mal ciego me sentía, sentéme como solía. Estando recibiendo aquellos dulces tragos, mi cara puesta hacia el cielo, un poco cerrados los ojos por mejor gustar el sabroso licor, sintió el desesperado ciego que agora tenía ya tiempo de tomar de mi venganza, y con toda su fuerza, alzando con dos manos aquel dulce y amargo jarro, le dejó caer sobre mi boca, ayudándose, como digo, con todo su poder, de manera que el pobre Lázaro, que de nada desto se guardaba, antes, como otras veces, estaba descuidado y gozoso, verdaderamente me pareció que el cielo, con todo lo que en él hay, me había caído encima» (p. 101)

La acumulación de construcciones circunstanciales en posición previa a la principal es extraordinaria: designan la situación confiada y tranquila en que se hallaba Lázaro, quien tan ajeno estaba de lo que se le preparaba que no llegó a saber en aquel momento qué le había ocurrido. Esas construcciones presentan una notable variedad: sintagmas sin preposición («luego otro día»), gerundios concertados, construcciones de «circunstancia concomitante» («mi cara puesta... )), sintagmas preposicionales, etc., y todas ellas tienen una misma caracterización «modal» desde el punto de vista semántico. No es en absoluto exclusivo del Lazarillo este amontonamiento de circunstancias previas (ya lo hemos visto en otros textos). Lo más notable es la perfecta adecuación de esa no progresividad sintáctica con lo que está hablando y el efecto que quiere producir; y, sobre todo, que ello se consigue mediante procedimientos variados dentro de su unidad, escasamente repetitivos (muy lejos, pues, del extremo paralelismo de otros textos) y acumulados con suma discreción. Verdaderamente, la prosa del Lazarillo, si bien presenta, como no podía ser menos, rasgos comunes con las de los otros textos, se mueve ya en otra dirección: es la prosa moderna, en efecto, desvinculada (pero ¿hasta qué punto?) del extremo seguimiento de los moldes retóricos clásicos. 